Received Date : 01-Jul-2014

Revised Date : 05-Sep-2014

Accepted Date : 10-Sep-2014

Article type : Research Article

\title{
The employment of a removable chitosan-derivatized polymeric sensitizer in the photooxidation of polyhydroxylated water-pollutants
}

\author{
Gabriela V. Ferrari ${ }^{1}$, María E. Andrada ${ }^{2}$, José Natera ${ }^{2}$, Vanesa A. Muñoz ${ }^{1}, M$. \\ Paulina Montaña ${ }^{1}$, Carolina Gambetta ${ }^{2}$, María L Boiero ${ }^{3}$, Mariana A. \\ Montenegro $^{3,4}$, Walter A. Massad ${ }^{2 *}$ and Norman A. García ${ }^{2 *}$
}

'Área de Química Física-INQUISAL, Universidad Nacional de San Luis, Lavalle 1151, 5700 San Luis, Argentine

${ }^{2}$ Departamento de Química, Universidad Nacional de Río Cuarto, Campus Universitario, 5800 Río Cuarto, Argentine

${ }^{3}$ Facultad Regional Villa María, Universidad Tecnológica Nacional, 5900 Villa María, Argentine

${ }^{4}$ Instituto de Ciencias Básicas y Aplicadas, Universidad Nacional de Villa María, Campus Universitario, 5900 Villa María, Argentine

*Corresponding authors: wmassad@exa.unrc.edu.ar ; ngarcia@exa.unrc.edu.ar Telephone: 543584676439

\section{Abstract}

The known $\mathrm{O}_{2}\left({ }^{1} \Delta_{\mathrm{g}}\right)$-sensitizer system Chitosan bounded Rose Bengal $(\mathrm{CH}-\mathrm{RB})$, with Rose Bengal (RB) immobilized by irreversible covalent bonding to the polymer Chitosan $(\mathrm{CH})$, soluble in aquous acidic medium, was employed in the This article has been accepted for publication and undergone full peer review but has not been through the copyediting, typesetting, pagination and proofreading process, which may lead to differences between this version and the Version of Record. Please cite this article as doi: $10.1111 / \mathrm{php} .12350$

This article is protected by copyright. All rights reserved. 
photodegradation of three tri-hydroxy benzene water-contaminants (THBs). The system sensitizes the $\mathrm{O}_{2}\left({ }^{1} \Delta_{\mathrm{g}}\right)$-mediated photodegradation of THBs by a process kinetically favored, as compared to that employing free RB dissolved in the same solvent. Additionally the free xanthene dye, degradable by $\mathrm{O}_{2}\left({ }^{1} \Delta_{g}\right)$ through selfsensitization upon prolonged light-exposure, is considerably protected when bonded to $\mathrm{CH}$-polymer. The polymeric sensitizer, totally insoluble in neutral medium, can be removed from the solution after the photodegradative cycle by precipitation through a simple $\mathrm{pH}$ change. This fact constitutes an interesting aspect in the context of photoremediation of confined polluted waters. In other words, the sensitizing system could be useful for avoiding to dissolve dyestuffs in the polluted waters, in order to act as conventional sunlight-absorbing dyesensitizers.

In parallel the interaction $\mathrm{CH}-\mathrm{O}_{2}\left({ }^{1} \Delta_{\mathrm{g}}\right)$ in acidic solution was evaluated. The polymer quenches the oxidative species with a rate constant $2.4 \times 10^{8} \mathrm{M}^{-1} \mathrm{~s}^{-1}$ being the process mostly attributable to a physical interaction. This fact promotes the photoprotection of the bonded dye in the $\mathrm{CH}-\mathrm{RB}$ polymer.

\section{Abbreviations}

$1,2,3$ THB,pyrogallol

1,2,4THB, 1,2,4-Trihydroxybenzene

$1,3,5 \mathrm{THB}$, Phloroglucinol

$\mathrm{CH}$, Chitosan

$\mathrm{CH}-\mathrm{RB}$, Chitosan-RB polymer

$\mathrm{D}_{2} \mathrm{O}$, Deuterium oxide

EDAC, N-(3-Dimethylaminopropyl)-N'-ethylcarbodiimide hydrochloride

FDA, Food and Drug Administration

FFA, Furfuryl alcohol

GRAS, Generally Recognized as Safe

$\mathrm{MeOH}$, methanol

This article is protected by copyright. All rights reserved. 
$\mathrm{NaN}_{3}$, Sodium azide

$\mathrm{O}_{2}\left({ }^{1} \Delta_{\mathrm{g}}\right)$, Singlet molecular oxygen

PN, Perinaphthenone

RB, Rose Bengal

ROS, Reactive oxygen species

THBs, tri-hydroxy benzene derivatives

TRPD, Time resolved phosphorescence detection

\section{Introduction}

Significant amounts of biocides are frequent contaminants of soils and surface waters (1) and their use in agriculture is normally conditioned by their persistence in the environment. As a consequence, the biological, thermal and photochemical pathways in the degradation of these contaminants are topics of an enormous research interest.

The photoinduced degradation in aerated water solution and under sunlight irradiation has been particularly tested with different degree of success, and the reactions involved have been studied in order to gain insight into the natural photochemical decay of all these substances. (2,3) The use of organic photocatalysts, especially in the UV range, constitutes an interesting alternative in the oxidation of pollutants. Important findings in this area has been recently reviewed by Marin et al. (4)

When the contaminant biocide does not absorb visible light, its decomposition in a natural aquatic environment can be carried out as well through its reaction with reactive oxygen species (ROS), if any colored compound is present in the medium. This compound, named photosensitizer, promotes the so called sensitized photo-degradative and in particular photo-oxidative reactions, that 
operate upon light absorption in the wavelength range of irradiation close to sunlight, in the presence of molecular oxygen. The overall process can be simplified by employing specific dye-sensitizers. The synthetic dye Rose Bengal $(\mathrm{RB})$ is a sensitizer that generates singlet molecular oxygen $\left(\mathrm{O}_{2}\left({ }^{1} \Delta_{\mathrm{g}}\right)\right)$ with high efficiency $(5,6)$. On the other hand, this xanthenic dye and similar $\mathrm{O}_{2}\left({ }^{1} \Delta_{\mathrm{g}}\right)$ generators could be used for a non-natural photochemical degradation of pollutants, in confined aqueous solutions and under controlled conditions. After an adequate photooxidative treatment, remediated waters could be discharged as waste waters with considerable diminution in their contamination risks. Nevertheless, at this point an essential problem remains: It is related to the difficulties in separation the intense colored photosensitizer from the reaction mixture at the end of the photooxidative cycle. Obviously these problems could be overcome by employing a removable heterogeneous system, with the photosensitizer covalently attached to an insoluble polymer chain. (7)

In the present work we employed a sensitizer system already described in the literature, in which the dye RB was immobilized by covalent bonding to the polymer chitosan (CH). (8) Similar systems employing other xanthene dyes (9), porphyrins and phthalocyanines, (10) immobilized on $\mathrm{CH}$ films have been tested for drug delivery and water disinfection.

The oxidizable target molecules we utilized in this work for modeling the water contaminants were three trihydroxybenzene derivatives (THBs). Due to their 
profuse use with industrial purposes $(11,12,13)$ THBs have been frequently found as contaminants in waste-waters. (14)

Chitosan ( $\beta-(1-4)-2-a m i n o-2-d e o x y-\beta-D-g l u c o s e$,$) is the second most naturally$ abundant polysaccharide next to cellulose, considered as GRAS (Generally Recognized as Safe) by Food and Drug Administration (FDA). $(15,16)$ Due to the hydroxyl and amino groups on its backbones, $\mathrm{CH}$ is a willing molecule that can be relatively easy modified by various methods. The solubility of $\mathrm{CH}$ in aqueous solution is highly dependent on $\mathrm{pH}$ (See Scheme 1 for a structural representation of $\mathrm{CH}$ ). The polymer can be dissolved in aqueous solution at acidic $\mathrm{pH}$, whereas it is totally insoluble in neutral medium (17). We took advantage of this property in the present work: The degradative photolysis of the pollutant was carried out at acidic $\mathrm{pH}$ employing the soluble chitosan-RB polymer (CH-RB). Following the polymer can be removed after the photodegradative cycle, by means of a simple change in the $\mathrm{pH}$ value of the solution.

The present contribution mimics, as closely as possible, a scenery consisting in a confined polluted water in the presence of oxygen, visible light and a removable RB-derivative as a dye-sensitizer. Under these conditions the photosensitizing efficiency of the soluble polymer $\mathrm{CH}-\mathrm{RB}$ and its ulterior extraction as a solid after the oxidative run was tested. The work constitutes a comparative study with the simple and conventional system represented free RB in solution. Besides, several properties of the very $\mathrm{CH}$ as quencher of $\mathrm{O}_{2}\left({ }^{1} \Delta_{\mathrm{g}}\right)$ under work conditions were investigated.

This article is protected by copyright. All rights reserved. 


\section{Materials and Methods}

\section{Materials}

Chitosan of low molecular weight, deuterium oxide $99.9 \%\left(D_{2} \mathrm{O}\right)$, Perinaphthenone (PN), N-(3-Dimethylaminopropyl)-N'-ethylcarbodiimide hydrochloride (EDAC) were purchased from Sigma Chem. Co. (St. Louis, MO, USA). Rose Bengal (RB), furfuryl alcohol (FFA), Phloroglucinol (1,3,5-THB), 1,2,4-THB, and Pyrogallol (1,2,3-THB) were bought from Aldrich (Milwaukee, WI, USA). Acetic acid and sodium hydroxide were from Cicarelli (Buenos Aires, Argentina). Methanol HPLC grade was from Sintorgan (Buenos Aires, Argentina). All these chemicals were used as received. Water was triply distilled. Buffered aqueous solutions were prepared, from acetic acid and sodium hydroxide (18). All measurements were made at room temperature.

\section{Methods}

$\mathrm{CH}$-RB was synthesized according to the procedures described in the works of Mansuri et al. and De Campos et al. (19,9) We dissolved $1 \mathrm{~g}$ of $\mathrm{CH}(70 \%$ deacetylation degree) in $80 \mathrm{~mL}$ of acetic acid $(1 \% \mathrm{v} / \mathrm{v})$ and the $\mathrm{pH}$ was adjusted to 5.9 by dropping a concentrated $\mathrm{NaOH}$ solution. Following, water was added to this solution to make the final volume of $100 \mathrm{~mL}$. Separately, $46 \mathrm{mg}$ of RB were dissolved in ethanol and $47 \mathrm{mg}$ of EDAC were added. This mixture was allowed to react for 20 minutes. Thereafter, both solutions were mixed up together and the resulting solution was brought to $\mathrm{pH} 5.9$ by drop wise addition of diluted aqueous $\mathrm{NaOH}$. Then the solution was stirred at room temperature in the dark for $18 \mathrm{~h}$. The 
resulting polymer was precipitated by the addition of $\mathrm{NaOH}$ up to a $\mathrm{pH}=8.5$ and washed successively with ethanol and the precipitate was then redissolved in acetic acid. $\mathrm{CH}-\mathrm{RB}$. The polymer was isolated by dialysis (cellulose membrane $12,400 \mathrm{Da}$, Sigma-Aldrich) against water (3 days) and then against a phosphate buffer $(\mathrm{pH}=7.4)$ for 2 days. Then the polymer was precipitated by adding a sodium hydroxide solution up to $\mathrm{pH}=8.5$; the precipitate was filtered and washed with methanol.

All steady-state photolysis were carried out at wavelengths $>400 \mathrm{~nm}$ (cut-off filter) employing a home-made photolyzer provided with a $150 \mathrm{~W}$ quartz-halogen lamp. Ground state absorption spectra were registered employing a Hewlett Packard 8452A diode array spectrophotometer.

The total quenching rate constant of deactivation of the $\mathrm{O}_{2}\left({ }^{1} \Delta_{\mathrm{g}}\right)$ by THBs or $\mathrm{CH}\left(k_{\mathrm{t}}\right.$, see further reactions [1] and [2], being $Q=\mathrm{CH}$ or $\mathrm{Q}=\mathrm{THBs}$ ) was determined using a system previously reported. (20) Briefly, it consisted a Nd:Yag laser (Spectron) as the excitation source. The emitted $\left(\mathrm{O}_{2}\left({ }^{1} \Delta_{\mathrm{g}}\right)\right)$ phosphorescence at $1270 \mathrm{~nm}$ was detected at right angles using an amplified Judson J16/8SP Germanium detector, after having passed through the appropriate filters. The output of the detector was coupled to a digital oscilloscope and to a personal computer to carry out the signal processing. Usually, 10 shots were needed for averaging so as to achieve a good signal to noise ratio, from which the decay curve was obtained. Air equilibrated solutions were employed in all cases.

This article is protected by copyright. All rights reserved. 
The concentration of the sensitizer (RB) was ca.0.02 mM. $D_{2} \mathrm{O}$ was used in the dynamic determinations, instead of $\mathrm{H}_{2} \mathrm{O}$ as solvent, in order to enlarge the lifetime of $\mathrm{O}_{2}\left({ }^{1} \Delta_{\mathrm{g}}\right) \cdot(21)$

In kinetic terms the interaction of $\mathrm{O}_{2}\left({ }^{1} \Delta_{\mathrm{g}}\right)$ with a given quencher $\mathrm{Q}$ can be depicted by reactions [1] and [2] representing respectively the physical and reactive deactivation of the excited oxidative species, where $\mathrm{O}_{2}\left({ }^{3} \Sigma_{g}{ }^{-}\right)$symbolizes ground state oxygen. The addition of the rate constants $k_{\mathrm{q}}$ and $k_{\mathrm{r}}$, is generically known as $k_{\mathrm{t}}$, the overall rate constant for the quenching of $\mathrm{O}_{2}\left({ }^{1} \Delta_{\mathrm{g}}\right)$.

$$
\begin{array}{ll}
\mathrm{O}_{2}\left({ }^{1} \Delta_{\mathrm{g}}\right)+\mathrm{Q} \longrightarrow \text { Products } & \text { rate constant } k_{\mathrm{r}}[1] \\
\mathrm{O}_{2}\left({ }^{1} \Delta_{\mathrm{g}}\right)+\mathrm{Q} \longrightarrow \mathrm{O}_{2}\left({ }^{3} \Sigma_{\mathrm{g}}{ }^{-}\right)+\mathrm{Q} & \text { rate constant } k_{\mathrm{q}}[2]
\end{array}
$$

For the determination of $k_{\mathrm{t}}$ (reactions (1) and (2)), the $\mathrm{O}_{2}\left({ }^{1} \Delta_{\mathrm{g}}\right)$ lifetimes were evaluated in the presence $(\tau)$ and in the absence $\left(\tau_{0}\right)$ of the quencher and the data were plotted according to a Stern-Volmer treatment (Equation [3]).

$\tau_{0} / \tau=1+k_{\mathrm{t}} \tau_{0}[\mathrm{Q}]$

The reactive rate constant $k_{\mathrm{r}}$ for the reaction of $Q$ with $\mathrm{O}_{2}\left({ }^{1} \Delta_{\mathrm{g}}\right)$ (reaction [2]), was determined using the method described by Scully and Hoigné (22) (Equation II), for which the knowledge of the reaction rate constant for the photo-oxidation of a reference compound $\mathrm{R}$ is required:

Slope $/$ slope $_{\mathrm{R}}=k_{\mathrm{r}}(\mathrm{Q}) / k_{\mathrm{rR}}(\mathrm{R})$

Where slope and slope $_{\mathrm{R}}$ are the respective slopes of their first-order plots of oxygen consumption by $Q$ and by a reference compound $R$ (each at the same concentration) under photoirradiation with visible-light in the presence of dye sensitizers. Assuming that the reaction of $\mathrm{O}_{2}\left({ }^{1} \Delta_{\mathrm{g}}\right)$ with the quencher is the only 
possible pathway of oxygen consumption, the ratio of the first order slopes of oxygen uptake by the substrate and the reference compound yields $k_{\mathrm{r}} / k_{\mathrm{rR}}$. The reference was FFA, with a reported $\mathrm{pH}$-independent $k_{\mathrm{rR}}$ value of $1.2 \times 10^{8} \mathrm{M}^{-1} \mathrm{~s}^{-1}$. (2) Rose Bengal and PN were employed as dye-sensitizers in the determination of $k_{\mathrm{r}}$ values for THBs and $\mathrm{CH}$ respectively. The rates of oxygen consumption were determined with the specific oxygen electrode Orion 97-08. The experimental array has been already described. (23)

The photodegradation rates of aqueous solutions of $\mathrm{RB}$ and $\mathrm{CH}-\mathrm{RB}$ were determined by monitoring the absorbance decrease in their respective absorption maxima in the visible spectral region, as a function of photoirradiation time.

For the evaluation of the percent of recovery of the solid polymer after dissolution in acidic aqueous solution, the following experiment was performed: $0.5 \mathrm{~g} \mathrm{CH}-\mathrm{RB}$ was dissolved in $50 \mathrm{ml}$ of $\mathrm{pH} 4.75$ buffered aqueous solution. and stirred during 15 min. The solution was neutralized by dropping a $0.5 \mathrm{M} \mathrm{NaOH}$ solution and the appearance of the precipitate $\mathrm{CH}-\mathrm{RB}$ was observed. The mixture was stored for $12 \mathrm{hs}$ in the dark and the solid fraction was quantitatively collected by vacuum filtration and washed three times with $15 \mathrm{ml}$ methanol. The solid was maintained in the dark at RT for $12 \mathrm{hs}$ and then in a stove at $80^{\circ} \mathrm{C}$ for $30 \mathrm{~min}$. After $2 \mathrm{hs}$ the solid was weight up to constant value. The experiment was made by triplicate and the mean value obtained for the recovery of the solid material was $98 \%$.

The $\mathrm{pH} / \mathrm{pD}$ values were controlled with a MP220 Mettler-Toledo $\mathrm{pH}$-metter. The $\mathrm{pD}$ value was calculated from the relation: $\mathrm{pD}=\mathrm{pH}$ reading $+0.4 .(24)$

This article is protected by copyright. All rights reserved. 


\section{Results and discussion}

Preparation of Chitosan-Rose Bengal polymer and stability of the polymer upon sensitized photoirradiation.

The polymer $\mathrm{CH}-\mathrm{RB}$, with a pinky powder aspect, was obtained by the amide linkage between the carboxylic group of the dye and the amino group of the polysaccharide, the presence of carbodiimide EDAC (Scheme 2). The mechanism, as described by Nakayima and Ikada, (25) includes the formation of carboxylicanhydride as intermediate; a step that is favored in the $\mathrm{pH}$ range 3.5-4.5.

The polymer was soluble in acidic water. We tested total dissolution up to $2 \% \mathrm{w} / \mathrm{w}$. The absorption spectrum of $\mathrm{CH}-\mathrm{RB}$ is significantly red shifted as compared to the absorption spectrum of free RB under identical experimental conditions, as shown in Fig.1, inset. This characteristic has been considered as an evidence for the attachment of the dye chromophore to the polymer. (8) The ratio of the absorbances at the absorption maxima $A_{l(561 \mathrm{~nm})} / A_{\| I(523 \mathrm{~nm})}=1.58$ (see spectrum "a" in Figure 1, inset), very close to the value of 1.6 reported in the literature for a well characterized $\mathrm{CH}-\mathrm{RB}$. (8)

For this compound, a value of the extinction coefficient $\varepsilon_{561}=45,000 \mathrm{~cm}^{-1} \mathrm{M}^{-1}$ has been employed. (8) We used this data to evaluate a value of 0.38 for the percentage of binding of the dye to $\mathrm{CH}$ polymer (the content of $\mathrm{RB}$ as a molar ratio with respect to the glucosamine unit of $\mathrm{CH}$ ). The employed composition of the polymer conjugates determine several properties: (a) Being ca. $70 \%$ of the $\mathrm{N}$ - 
acetylglucosamine units of chitin deacetylated, this proportion enables a solubility window for the $\mathrm{CH}-\mathrm{RB}$ polymer that warrants adequate light absorption. (b) The above mentioned percentage of binding dye-polymer is high enough to generate $\mathrm{O}_{2}\left({ }^{1} \Delta_{\mathrm{g}}\right)$ upon adequate photoirradiation and low enough to avoid self-quenching of $\mathrm{RB}$ excited states by the ground state of the dye.

Regarding the photostabiliry of the $\mathrm{CH}-\mathrm{RB}$, it is known that dissolved $\mathrm{RB}$ is photolabile. There are a large number of publications about the photopromoted processes/degradation of $\mathrm{RB}$ under oxidative and reducing conditions in aerobic and deoxygenated media. $(26,27,28)$. Nevertheless no information about possible oxidation products was given in those papers. Semiconductor catalysis has also been employed for RB photodestruction. The sensitized oxidation leads to mineralization. (29) The kinetics of RB degradation was studied by means of oxygen photoconsumption measurements. The reaction was first order in dye concentration, and the apparent order with respect to oxygen depends on the oxygen/dye ratios. The stoichiometry of the reaction resulted approximately 2 oxygen molecules consumed per molecule of $\mathrm{RB}$, and reaction intermediates were detected. (30). A rate constant $k_{\mathrm{t}}=2 \times 10^{7} \mathrm{M}^{-1} \mathrm{~s}^{-1}$ for the $\mathrm{O}_{2}\left({ }^{1} \Delta_{\mathrm{g}}\right)$-mediated process has been reported for $\mathrm{RB}$ in $\mathrm{MeOH}$ (31). The photodegradation rate of the dye can be monitored by decrease of the absorbance maximum as a function of photoirradiation time. In order to evaluate the stability of the dye bonded to the polymer in $\mathrm{CH}-\mathrm{RB}$, individual solutions of $\mathrm{CH}-\mathrm{RB}$ and the free $\mathrm{RB}$ with matched absorbances at the irradiation wavelength were photolyzed with light of $550 \pm 10$ nm. Results are shown in Figure 1, main. As can be clearly seen the 
photodegradation rate of the polymer-bonded $\mathrm{RB}$ is $\mathrm{ca}$. five times lower than the free dye, under the described conditions. Assuming a similar fraction of absorbed light for both compounds, a plausible reason for the mentioned difference may due to the presence of the polysaccharide moiety in the $\mathrm{CH}-\mathrm{RB}$ derivative exerting a sort of protection on the $\mathrm{O}_{2}\left({ }^{1} \Delta_{\mathrm{g}}\right)$-mediated degradation of the bonded dye. Then this possibility was evaluated as follows.

The interaction Chitosan $-\mathrm{O}_{2}\left({ }^{1} \Delta_{g}\right)$

All experiments involving possible $\mathrm{O}_{2}\left({ }^{1} \Delta_{\mathrm{g}}\right)$-mediated processes on $\mathrm{CH}-\mathrm{RB}$ at $\mathrm{pH} / \mathrm{pD}$ 4.5 were carried out employing the exclusive $\mathrm{O}_{2}\left({ }^{1} \Delta_{g}\right)$-generator dye PN. It is one of the sensitizers most frequently used in $\mathrm{O}_{2}\left({ }^{1} \Delta_{g}\right)$ reactions with a reported quantum yield for the production of the oxidative species of ca. 1 in aqueous solution. (32)

The presence of $\mathrm{CH}(70 \%$ deacetylation degree) in the sub-mM concentration range quenches the IR phosphorescence emission of $\mathrm{O}_{2}\left({ }^{1} \Delta_{\mathrm{g}}\right)$, as detected by TRPD experiments. A rate constant $k_{t}=2.4( \pm 0.2) \times 10^{8} \mathrm{M}^{-1} \mathrm{~s}^{-1}$ for the overall interaction $\mathrm{O}_{2}\left({ }^{1} \Delta \mathrm{g}\right)-\mathrm{CH}$ was independently determined in pD $4.75 \mathrm{D}_{2} \mathrm{O}$ through a Stern-Volmer treatment (Figure 2, main). This experiment unambiguously demonstrates the existence of this interaction, which may be reactive in nature (reaction [1]) and/or a mere physical process (reaction [2]). The $k_{t}$ values, as determined by TRPD, do not depend on the type of sensitizer or on potential interactions of the substrate with excited states of the sensitizer involved in the $\mathrm{O}_{2}\left({ }^{1} \Delta_{\mathrm{g}}\right)$ generation. An inspection on the $\mathrm{CH}$ chemical structure, looking for 
recognized $\mathrm{O}_{2}\left({ }^{1} \Delta \mathrm{g}\right)$-quenchers, only identifies the primary amino groups as potential candidates. The reported $k_{\mathrm{t}}$ values for such compounds are in the range of $4 \times 10^{5} \mathrm{M}^{-1} \mathrm{~s}^{-1}$ as a mean value. (2) Nevertheless, considering that $\mathrm{CH}$ is formed by ca. 1300 glucosamine units, i.e.1300 primary amino groups, the $k_{t}$ value of $5 \times 10^{8}$ $\mathrm{M}^{-1} \mathrm{~s}^{-1}$ roughly matches a value that would correspond to the approximate bulk concentration of primary amino groups in the polymer aqueous solution.

A rate constant value value $k_{r}=2.7( \pm 0.1) \times 10^{7} \mathrm{M}^{-1} \mathrm{~s}^{-1}$ for $\mathrm{CH}$ (reaction [1]) was determined in $\mathrm{pH} 4.75$ aqueous solution by monitoring oxygen consumption upon photoirradiation of $\mathrm{PN}-\mathrm{CH}$ mixtures, following a described method.(22) The calculated $k_{\mathrm{r}} / k_{\mathrm{t}}=0.11$ ratio represent a measure of the efficiency of the degradation pathway of $\mathrm{CH}$ via reaction with $\mathrm{O}_{2}\left({ }^{1} \Delta_{g}\right)$. The relatively low $k_{r} / k_{t}$ value obtained for $\mathrm{CH}$ indicates, as a final result, the elimination of the oxidative species $\mathrm{O}_{2}\left({ }^{1} \Delta_{\mathrm{g}}\right)$ without appreciable loss of the scavenger. This behaviour could explain the observed protective effect on the degradability of the polymer-bonded RB, through a physical quenching of $\mathrm{O}_{2}\left({ }^{1} \Delta_{\mathrm{g}}\right)$ exerted by the polymeric $\mathrm{CH}$ moiety.

The main activity of $\mathrm{CH}$ as a physical quencher of $\mathrm{O}_{2}\left({ }^{1} \Delta_{\mathrm{g}}\right)$ is also expected and characteristic for compounds with a prevalent presence of primary amino groups. Je and Kim, Pasanphan and Chirachanchai, among other researchers, investigated on the antioxidant properties of $\mathrm{CH}$ and $\mathrm{CH}$-based derivatives against different ROS, including superoxide anion, hydroxyl radicals and hydrogen peroxide. $(33,34)$ The topic has recently been reviewed by Luo and Wang and no reports on the activity of the polymer towards $\mathrm{O}_{2}\left({ }^{1} \Delta_{\mathrm{g}}\right)$ were included. (17) In this 
context and acording to our knowledge, this is the first quantitative report on the interaction between the polymer dissolved in aqueous solution and photogenerated $\mathrm{O}_{2}\left({ }^{1} \Delta_{\mathrm{g}}\right)$.

Degradation of THBs employing $\mathrm{CH}-\mathrm{RB}$ photosensitization

In a previous paper we reported a kinetic study on the RB-sensitized photodegradation of $1,2,4-\mathrm{THB} ; 1,2,3-\mathrm{THB}$ and $1,3,5-\mathrm{THB}$ in $\mathrm{pH} 2$ aqueous solution. (35) THBs were photodegraded through a $\mathrm{O}_{2}\left({ }^{1} \Delta_{\mathrm{g}}\right)$-mediated photooxidative process, as depicted by reaction (1). Possible photoproducts are quinonic compounds, typically formed in $\mathrm{O}_{2}\left({ }^{1} \Delta_{\mathrm{g}}\right)$-mediated reactions of phenols. (14). Hydroxyquinonic derivatives have been also reported as photoproducts in the direct photolysis of aqueous THBs in the presence of oxygen. (36) The photoirradiation of the mixture $\mathrm{CH}-\mathrm{RB}(0.052 \% \mathrm{w} / \mathrm{v})$ plus $0.2 \mathrm{mM} 1,2,4-\mathrm{THB}$; 1,2,3-THB and 1,3,5-THB in $\mathrm{pH} 4.75$ water (>350 nm, cut off filter) produced neat changes in the absorption spectra of the THBs. In Figure 3 is shown the case of 1,2,4-THB employing the sensitizer $\mathrm{CH}-\mathrm{RB}$, as a typical example. No spectral changes were observed when the same photoirradiation was performed in the absence of $\mathrm{CH}-\mathrm{RB}$ for any of the THBs .

In parallel, photoirradiation of the same solutions under identical experimental conditions gave rise to oxygen consumption. The rate of Oxygen uptake was neatly decreased in the presence of $\mathrm{NaN}_{3} 0.6 \mathrm{mM}$, as shown in Figure 4, inset. The salt is a well known $\mathrm{O}_{2}\left({ }^{1} \Delta_{\mathrm{g}}\right)$ scavenger, with a reported $k_{\mathrm{t}}$ value of $2.08 \times 10^{9} \mathrm{M}^{-1} \mathrm{~s}^{-1}$. It is 
profusely employed to confirm/discard the involvement of the oxidative species in a given photoprocess. (2) This result in addition to the reported value of 0.83 for the quantum yield of $\mathrm{O}_{2}\left({ }^{1} \Delta_{\mathrm{g}}\right)$ generation by the polymer $\mathrm{CH}-\mathrm{RB}$, (8) strongly suggest that the observed degradation of THBs is due to a $\mathrm{O}_{2}\left({ }^{1} \Delta_{\mathrm{g}}\right)$-mediated photooxidative process, similar to the already described for THBs, photosensitized by free RB. (35). However, a contribution from hydroperoxyl radical $\left(\mathrm{HO}_{2}{ }^{\circ}\right)$ to the overall oxidative process should not be disregarded. It is known that photoexcited RB may, in a minor extent, generate the species superoxide radical anion $\left(\mathrm{O}_{2}{ }^{--}\right)$that is protonated in acidic medium to form the species $\mathrm{HO}_{2}{ }^{\bullet}$ which is easily reduced by many aromatic electron donors. $(37,38)$

Figure 4 shows the first order plot employed for the determination of the respective $k_{\mathrm{r}}$ values of THBs, resulting $0.68 \times 10^{8} \mathrm{M}^{-1} \mathrm{~s}^{-1} ; 1.44 \times 10^{8} \mathrm{M}^{-1} \mathrm{~s}^{-1}$ and $1.00 \times 10^{8} \mathrm{M}^{-}$ ${ }^{1} \mathrm{~s}^{-1}$ for $1,2,3$-THB $1,3,5-\mathrm{THB}$ and 1,2,4-THB. These $k_{\mathrm{r}}$ values lie within the expected order of magnitude of those for poly-hydroxybenzenes in acidic/neutral aqueous solutions reported by other authors. $(14,39,40)$

In Figure 5 both the $k_{\mathrm{r}}$ values obtained in $\mathrm{pH} 4.75$ water, employing $\mathrm{CH}-\mathrm{RB}$ as a photosensitizer, and those already reported in $\mathrm{pH} 2$ water employing the free dye, (35) are compared by means of a logarithmic bars diagram. As can be seen, in all cases the rate constants determined employing the polymeric sensitizer are appreciably higher than the corresponding ones for the system with free $\mathrm{RB}$ as a sensitizer.

The reported quantum yield of ca. 0.83 by $\mathrm{CH}-\mathrm{RB}$ is ca. $7 \%$ higher than that of 
the free dye. (8) In principle this factor does not appear as the only responsible for the remarkable photodegradation-rate increase exerted by the polymer-bonded RB sensitization. On the other hand, this effect contrasts to some degree with the above mentioned photoprotection exhibited by the polymer against $\mathrm{O}_{2}\left({ }^{1} \Delta_{g}\right)$ attack. We think that the increase in the $k_{r}$ values could be due to an increase in the local concentration of the THBs nearby the sites of generation of the oxidative species. In that case the $\mathrm{O}_{2}\left({ }^{1} \Delta_{g}\right)$ diffusion to the reaction site -one of the limiting steps in the whole photosensitization/photooxidation process- is minimized as compared to an scenery of homogeneous distribution of the oxidizable substrate. Concomitantly, the physical quenching of the oxidiative species by the primary amino groups of the polymer bone, should be also decreased. A similar model has been already employed by Zhang et al. to interpret the efficiency increase in $\mathrm{O}_{2}\left({ }^{1} \Delta_{\mathrm{g}}\right)$-mediated reactions by comparing free hematoporphyrin and hematoporphyrin -doped silica nanoparticles as photosensitizers with an anthracene derivative as oxidizable target. (41).

Finally, a significant increase in the $k_{\mathrm{r}}$ values due to ionization of the $\mathrm{OH}$ groups of the THBs on going from $\mathrm{pH} 2$ (homogeneous sensitizer) to $\mathrm{pH} 4.75$ (heterogeneous sensitizer) must be disregarded. (14). The reported pK values for the first ionization of THBs are, in all cases, higher than 7. $(35,42)$.

Recuperation of the solid polymer after dissolution.

The evaluation of the percent of recovery of the solid polymer bonded to RB was performed by dissolving $0.5 \mathrm{~g} \mathrm{CH}-\mathrm{RB}$ in $50 \mathrm{ml}$ of $\mathrm{pH} 4.75$ aqueous solution. An 
absorbance value of 0.9 was registered in the spectral maximum at $560 \mathrm{~nm}$ for a dilution $1: 10$ of this solution vs. the $\mathrm{pH} 4.75$ aqueous solution. The operation was repeated after 3 hs storage of the concentrated solution in the dark under continuous stirring, and the original absorbance value was maintained. The whole procedure, described in the experimental section, was made by triplicate with a mean value of $97.9+0.2$. A mean absorbance value in the wavelength range 550 $570 \mathrm{~nm}$, determined for a dilution $1: 10 \mathrm{v} / \mathrm{v}$ of the supernatant fraction, was lower than 0.01.This result demonstrates that in practise the loss of RB bonded to the polymer is negligible.

\section{Final remarks}

Results in the present contribution demonstrates that the polymer $\mathrm{CH}-\mathrm{RB}$ can photosensitize the $\mathrm{O}_{2}\left({ }^{1} \Delta_{\mathrm{g}}\right)$-mediated degradation of THBs in acidic aqueous solution. In this particular case the photodegradative process is kinetically favored as compared to the conventional one, employing RB straightforwardly dissolved in aqueous solution. Additionally the sensitizer, degradable by $\mathrm{O}_{2}\left({ }^{1} \Delta_{\mathrm{g}}\right)$ through selfsensitization upon prolonged light- exposure, is considerably protected when bonded to $\mathrm{CH}$-polymer. The polymeric sensitizer can be removed from the solution after simple neutralization.

\section{Scheme and Figure captions}

\section{Scheme 1.}

Chemical structure of Chitosan

\section{Scheme 2.}

This article is protected by copyright. All rights reserved. 
Chemical structure of the polymer Chitosan-Rose Bengal

Figure 1.

Absorbance changes as a function of photoirradiation time in solutions of $\mathrm{CH}-\mathrm{RB}$ (a) and RB (b) with matched absorbances at $550 \mathrm{~nm}$, in $\mathrm{pH} 4.75$ aqueous solutions, monitored at 561 and $548 \mathrm{~nm}$ respectively. Inset: Normalized electronic absorption spectra of the polymer $\mathrm{CH}-\mathrm{RB}$ (a) and $\mathrm{RB}$ (b) in their respective maxima, in $\mathrm{pH} 4.75$ aqueous solution. $A_{l}$ and $A_{\| l}$ are the absorbance values for the maximum and the shoulder of a solution of $\mathrm{CH}-\mathrm{RB}$ in $\mathrm{pH} 4.75$ aqueous solution.

Figure 2.

Stern-Volmer plots for the quenching of $\mathrm{O}_{2}\left({ }^{1} \Delta_{\mathrm{g}}\right)$ phosphorescence by $\mathrm{CH}$ in $\mathrm{pD}$ 4,75 aqueous solution. $T$ and $T_{0}$ are the respective $\mathrm{O}_{2}\left({ }^{1} \Delta_{g}\right)$ phosphorescence lifetimes in the presence and in the absence of $\mathrm{CH}$. Inset: first order plots for oxygen uptake in $\mathrm{pH} 4,75$ aqueous solution by $\mathrm{CH}$ (a) and FFA (b). $\mathrm{RB}$ ( $A_{548}=$ $0.5)$ as a sensitizer.

\section{Figure 3.}

Changes in the UV-Vis absorption spectrum of a $\mathrm{pH} 4.75$ aqueous solution of 1,2,4-THB plus $\mathrm{CH}-\mathrm{RB}\left(A_{561}=0.6\right)$ vs. $\mathrm{CH}-\mathrm{RB}\left(A_{561}=0.6\right)$. Inset: Absorbance decrease of the described system as a function of photoirradiation time, monitored at $291 \mathrm{~nm}$.

Figure 4.

First order plots for oxygen uptake in $\mathrm{pH} 4,75$ aqueous solution by $1,2,3$-THB (a); 1,2,4-THB (b); 1,3,5-THB (c) and FFA (d) photosensitized by CH-RB $(0.052 \% \mathrm{w} / \mathrm{v})$. Inset: oxygen consumption as a function of photoirradiation time by the following $\mathrm{pH} 4,75$ aqueous solutions: $\mathrm{CH}-\mathrm{RB}(0.052 \% \mathrm{w} / \mathrm{v})$ plus $0.5 \mathrm{mM} \mathrm{1,3,5-THB}$ (b) and $\mathrm{CH}-\mathrm{RB}(0.052 \% \mathrm{w} / \mathrm{v})$ plus $0.5 \mathrm{mM} 1,3,5-\mathrm{THB}$ plus $0.6 \mathrm{mM}$ sodium azide (a).

\section{Figure 5.}

Values of $\log k_{\mathrm{r}}$ for 1,2,3-THB; 1,2,4-THB and 1,3,5-THB in $\mathrm{pH} 4,75$ aqueous solution photosensitized by $\mathrm{CH}-\mathrm{RB}$ (lined bars) and the same at $\mathrm{pH} 2$, photosensitized by RB (empty bars).

\section{References}

1.Tomlin, C. (1994) The pesticide manual.British Crop Protection Council and The Royal Society of Chemistry, London, UK.

2. Wilkinson, F., W.P. Helman, and A.B. Ross (1995) Rate constants for the decay and reactions of the lowest electronically excited singletstate of molecular oxygen in solution. An expanded and revised compilation. J. Phys. Chem. Ref. Data 24, 663-1021.

This article is protected by copyright. All rights reserved. 
3. Burrows, H.D., M. Canle L, J.A. Santaballa, and S. Steenken (2002) Reaction pathways and mechanisms of photodegradation of pesticides.J. Photochem. Photobiol. B: Biol. 67, 71-108.

4. Marin, M. L., L. Santos-Juanes, A. Arques, A. M. Amat, and M. A. Miranda (2012) Organic Photocatalysts for the Oxidation of Pollutants and Model Compounds. Chem. Rev., 112, 1710-1750.

5. Neckers, D.C. (1989) Rose Bengal. J.Photochem. Photobiol. A: Chem. 47, 1-29.

6. Amat-Guerri, F., M.M.C. López-González, R. Martínez-Utrilla, and R. Sastre (1990) Singlet oxygen photogeneration by ionized and un-ionized derivatives of Rose Bengal and Eosin Y in diluted solutions. J. Photochem. Photobiol. A: Chem. 53, 199-210.

7. Gryglik D., J. S. Miller and S. Ledakowicz (2004) Solar energy utilization in degradation of 2-chlorophenol by immobilized photosensitizers. Sol. Energy 77, 615-623.

8. Moczek, L. and M. Nowakowska (2007) Novel Water-Soluble Photosensitizers from Chitosan.Biomacromolecules, 8, 433-438.

9. De Campos, A., Y. Diebold, E. Carvalho, A. Sánchez, and M. José Alonso (2004) Chitosan Nanoparticles as New Ocular Drug Delivery Systems: in Vitro Stability, in Vivo Fate, and Cellular Toxicity. Pharm.. Res. 21, 803-810.

10. Bonnet, R., M. A. Kristeva, I. G. Lalov and S. V. Srtarsky (2006) water disinfection using photosensitizers immobilized on chitosan. Water Res. 40, 12961275.

11. Fieser, L. F. and M. Fieser (1948) QuímicaOrgánica. Ed. Atlante, México.

12. Schwarz, K., E.N. Frankel, and J.B. German (1996) Partition behaviour of antioxidative phenolic compounds in heterophasic systems. Fett/Lipid. 98, 115121.

13. Davidson, R.S., H. Choudhury, S. Origgi, A. Castellan, V. Trichet, and G. Capretti (1995) The reaction of phloroglucinol in the presence of acid with lignincontaining materials. J. Photochem. Photobiol. A: Chem. 91, 87-93.

14. Garcia, N.A. (1992) Environmental significance of singlet molecular oxygenmediated degradation of phenolic aquatic pollutants. J. Photochem. Photobiol. B: Biol. 14, 381-383.

This article is protected by copyright. All rights reserved. 
15. Martínez-Camacho, A.P., M.O. Cortez-Rocha, J.M. Ezquerra-Brauer, A.Z. Graciano-Verdugo, F. Rodriguez-Félix, M.M. Castillo-Ortega and M. S.Yepiz (2010) Chitosan composite films: Thermal, structural, mechanical and antifungal properties. Carbohyd. Polym. 82, 305-315.

16. Wondraczek, H, A. Kotiaho, P. Fardim and T. Heinze (2011) Photoactive Polysaccharides. Carbohyd. Polym. 83, 1048-1061.

17. Luo, Y., and Q. Wang (2013) Recent Advances of Chitosan and Its Derivatives for Novel Applications in Food Science. J Food Process. Bever. 1, 1-13.

18. Weast,R.C. (1974) Handbook of Chemistry and Physics, USA: CRC Press, pp. 1974.

19. Mansouri, S., Y. Cuie, F. Winnik, Q. Shi, P. and P. Lavigne, M. Benderdour, E. Beaumont and J. C. Fernandes (2006) Characterization of folate-chitosan-DNA nanoparticles for gene therapy. Biomaterials, 27, 2060-2065.

20. Neumann, M.M., S.N. Fusero and N.A. García (1991) A comparative study on the susceptibilities of soybean, sunflower and peanut oils to singlet molecular oxygen photooxidation. J. Am. Oil. Chem. Soc. 68, 662-665.

21. Nonell, S., L. Moncayo, F. Trull, F. Amat-Guerri, E.A. Lissi, A.T. Soltermann, S. Criado, and N.A. Garcia (1995) Solvent influence on the kinetics of the photodynamic degradation of trolox, a water-soluble model compound for vitamin E. J. Photochem. Photobiol. B: Biol. 29, 157-162.

22. Scully, F.E., and J. Hoigne (1987) Rate constants for the reaction of singlet oxygen with phenols and other compounds in water. Chemosphere, 16, 694-699.

23. Palumbo, M. C., N. A. García and G. A. Argüello (1990) Reactive and physical quenching of singlet molecular oxygen $\left(\mathrm{O}_{2}\left({ }^{1} \Delta_{\mathrm{g}}\right)\right)$ by indolic derivatives. J. Photochem. Photobiol. B: Biol, 7, 33-42.

24. Glasoe, PK and F. A. Long (1960). Use of glass electrodes to measure acidities in deuterium oxide. J. Phys. Chem. 64, 188-1899.

25. Nakajima, N. and Y. Ikada (1995) Mechanism of Amide Formation by Carbodiimide for Bioconjugation in Aqueous Media. Bioconjugate Chem. 6, 123130.

26. Zakrzewski, A. and D.C. Neckers (1987). Bleaching products of rose bengal under reducing conditions. Tetrahedron, 43, 4507-4512.

This article is protected by copyright. All rights reserved. 
27. Tonogai, Y., Y. Ito, M. Iwida, M. Tati, J. Ose, T. Sato (1979) Studies on the toxicity of coal-tar Dyes. I. Photodecomposed products of four xanthenes dyes and their acute toxicity to fish. J. Toxicol. Sci. 4, 115-126.

28 Xiong H., E. Buck, J. Stuart, I. N. Pessah, G. Salama and J. J. Abramson (1992) Rose bengal activates the $\mathrm{Ca}^{2+}$ release channel from skeletal muscle sarcoplasmic reticulum. Arch. Biochem. Biophys. 292, 522-528.

29. Tennakone, R., W. C. B. Kiridena and S. Punchihewa (1992). Photodegradation compounds in the presence of semiconductor of visible-lightabsorbing organic catalysts. Photochem. Photobiol. A: Chem. 389, 389-393

30. Wilson W. W. and J. R. Heitz (1984) Consumption during Photobleaching of Aqueous Solutions of Rose Bengal. J. Agric. Food Chem. 32, 615-617.

31.Lissi, E. A., M.V. Encinas, E. Lemp, and M.A. Rubio (1993) Singlet oxygen $\mathrm{O}_{2}\left({ }^{1} \Delta_{\mathrm{g}}\right)$ bimolecular processes. Solvent and compartmentalization effects. Chem. Rev. 93, 699-723.

32.Wilkinson, F., W.P. Helman, and A.B. Ross (1993) Quantum Yields for the Photosensitized Formation of the Lowest Electronically Excited Singlet State of Molecular Oxygen in Solution. J.Phys.Chem.Ref.Data. 22, 113-262.

33.Je, J.-Y., and S.-K.Kim (2006) Reactive oxygen species scavenging activity of aminoderivatized chitosan with different degree of deacetylation.Bioorg. Med. Chem. 14, 5989-5994.

34 . Pasanphan, W. and S. Chirachanchai (2008) Conjugation of gallic acid onto chitosan: An approach for green and water-based antioxidant. Carbohyd. Polym. 72, 169-177

35. Gutiérrez, M.I., A.T. Soltermann, F. Amat-Guerri, and N.A. García (2000) Kinetics of the dye-sensitized photooxidation of trihydroxybenzenes. J. Photochem. Photobiol. A: Chem. 136, 67-71.

36. Perbet, G., P. Boule and J. Lemaire (1982) Photochimie et environment II. Photochimie dees triphenols en solution aqueuse diluee. J. Chim. Phys.-Chim. Biol, 79, 95-100.

37. Lambert, C. R. and I. E. Kochevar (1996) Does Rose Bengal Triplet Generate Superoxide Anion? J. Am. Chem. Soc. 118, 3297-3298.

38. I.B. Afanas'ev (1989) Superoxide Ion: Chemistry and Biological Implications, vol. 1, pp 50-51,CRC Press, Boca Raton, FL.

This article is protected by copyright. All rights reserved. 
39. Tratnyek P. G. and J. Hoigné (1991) Oxidation of substituted phenols in the environment. A QSAR analysis of rate constants for reaction with singlet oxygen. Environ. Sci. Technol. 25, 1596-1604.

40. Márftire, D. O. and M. C. González (2000) Quantitive structure-activity relationship (QSAR) for reactions of singlet molecular oxygen with phenols. Rec. Res. Devel. Photochem. Photobiol. 4, 271-280.

41. Zhang, R., C. Wu, L. Tong, B. Tang, and Q.-H. Xu (2009) Multifunctional Core-Shell Nanoparticles as Highly Efficient Imaging and Photosensitizing Agents. Langmuir, 25, 10153-10158.

42. Wang, D., Y. György, K. Hildenbrand and C. von Sonntag (1994) Free radical induced oxidation of phloroglucinol. A pulse radiolysis and EPR study. J. Chem. Soc. Perkin Trans. 2, 45-55.

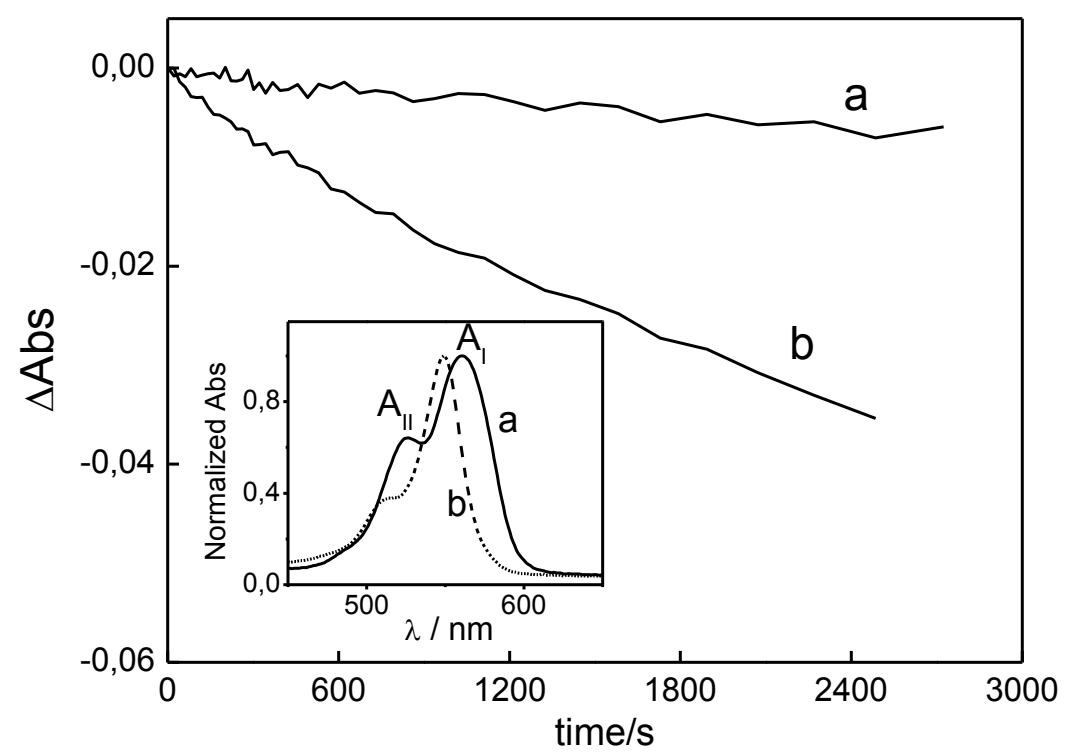

Figure 1

This article is protected by copyright. All rights reserved. 


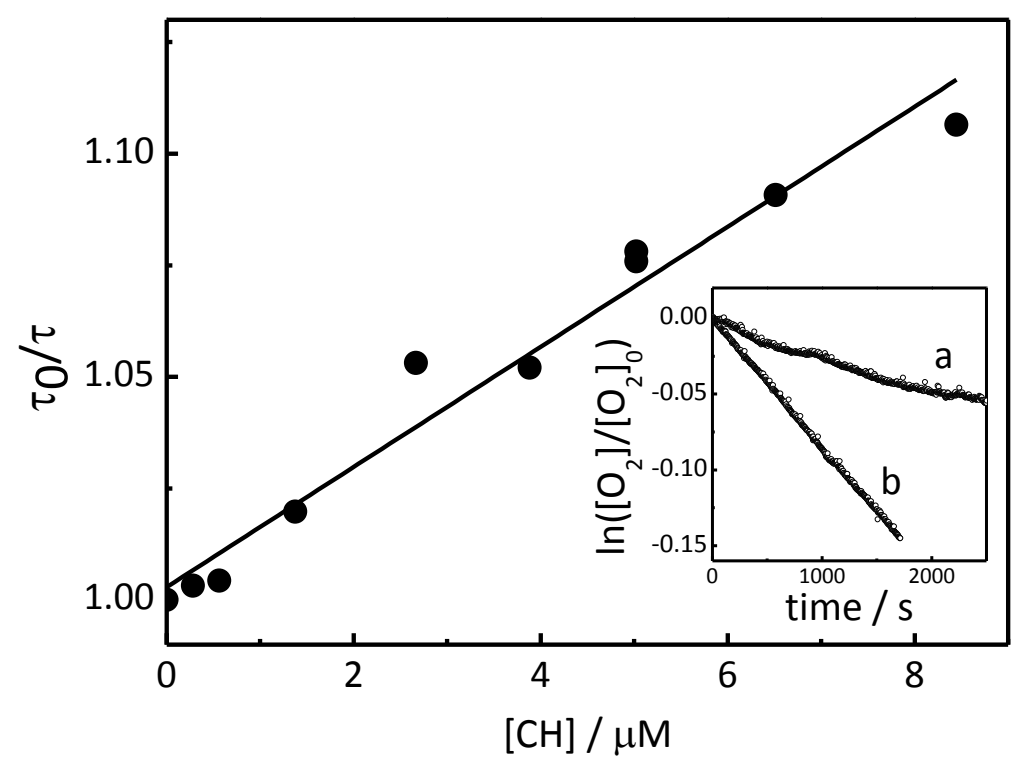

Figure 2

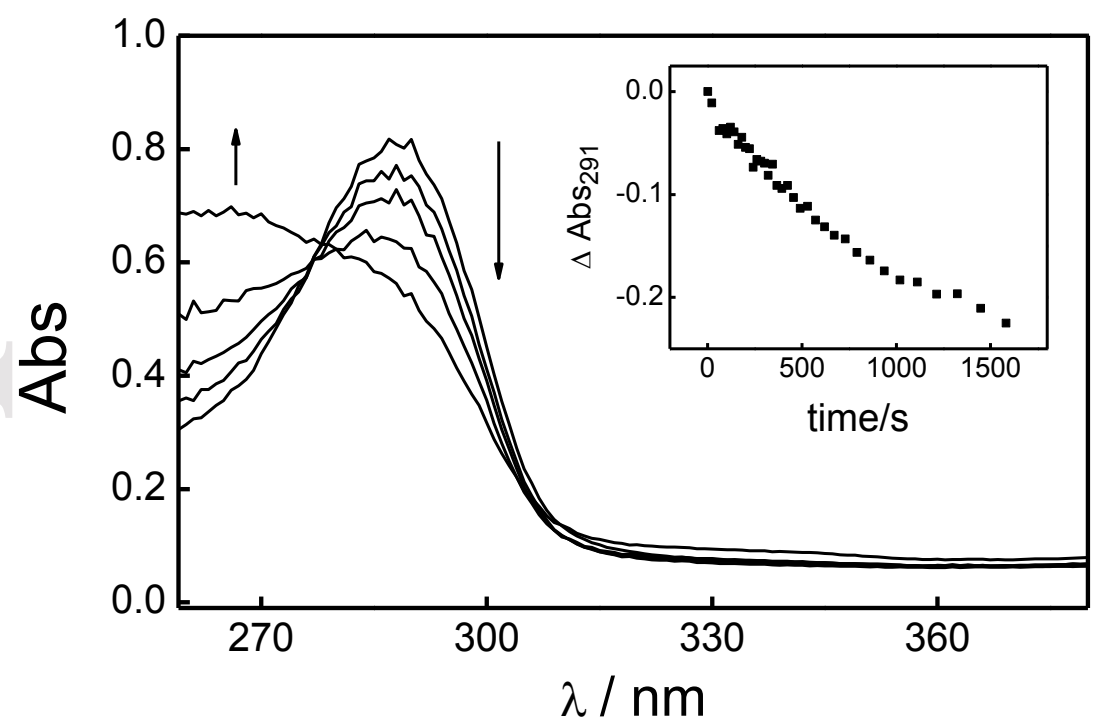

Figure 3

This article is protected by copyright. All rights reserved. 


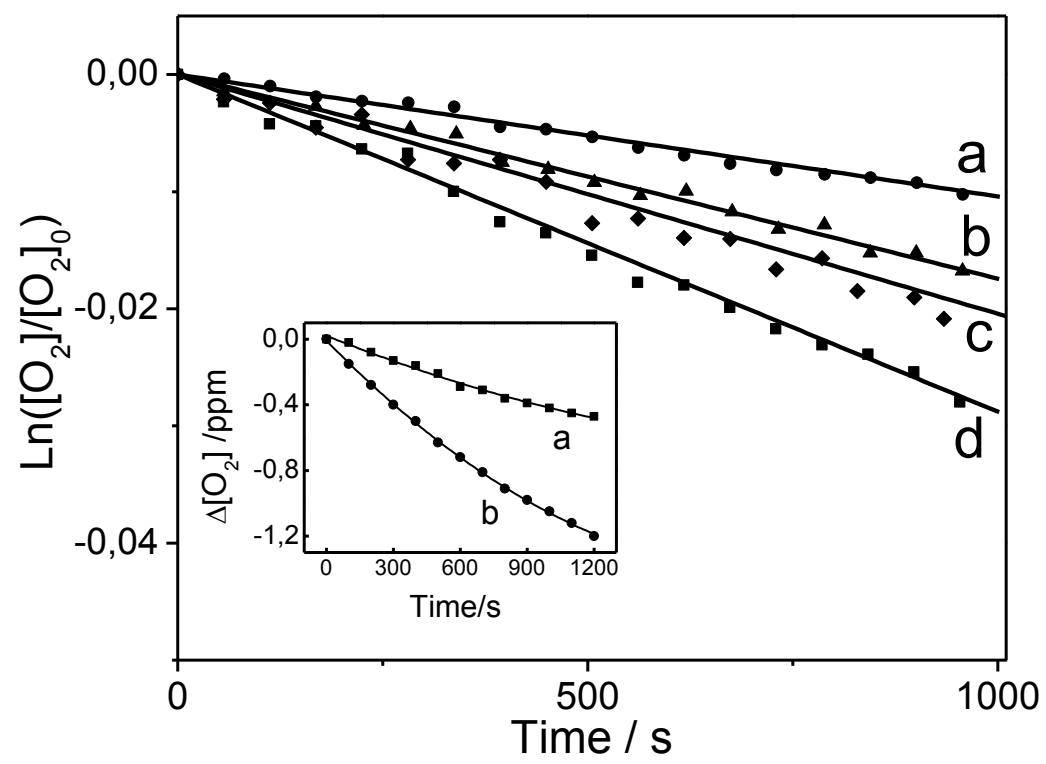

Figure 4

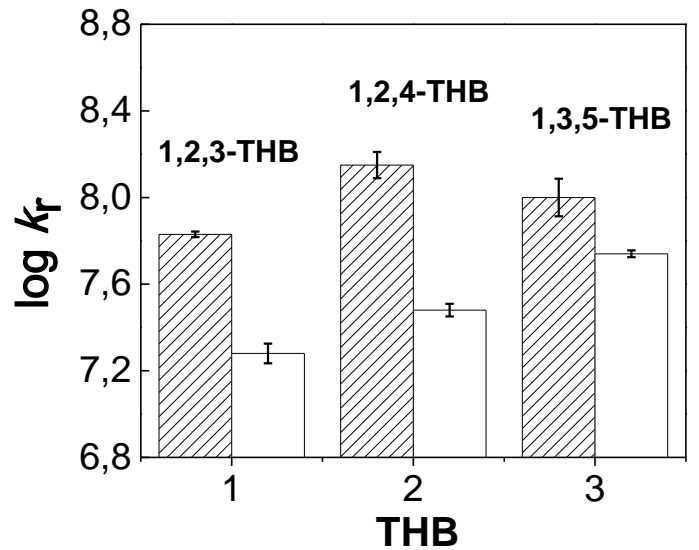

Figure 5

This article is protected by copyright. All rights reserved. 


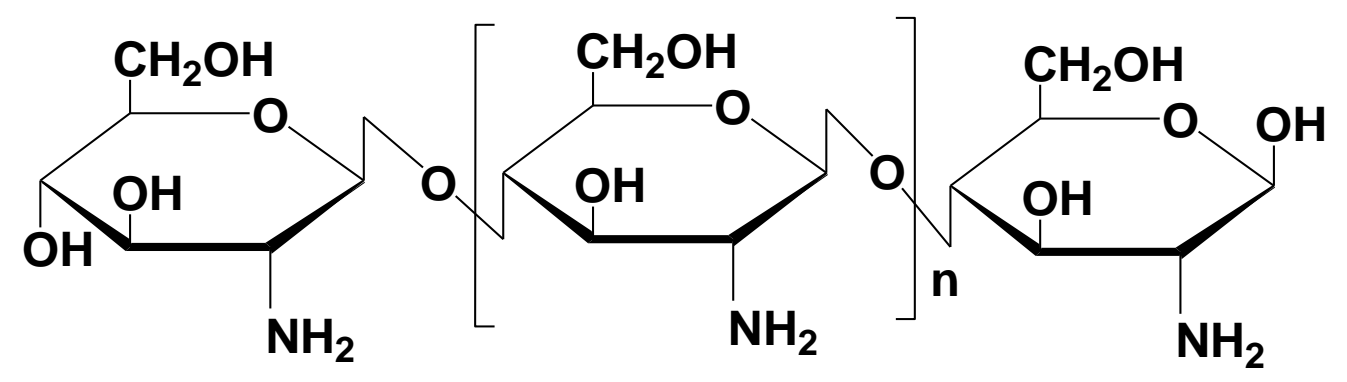

Scheme 1

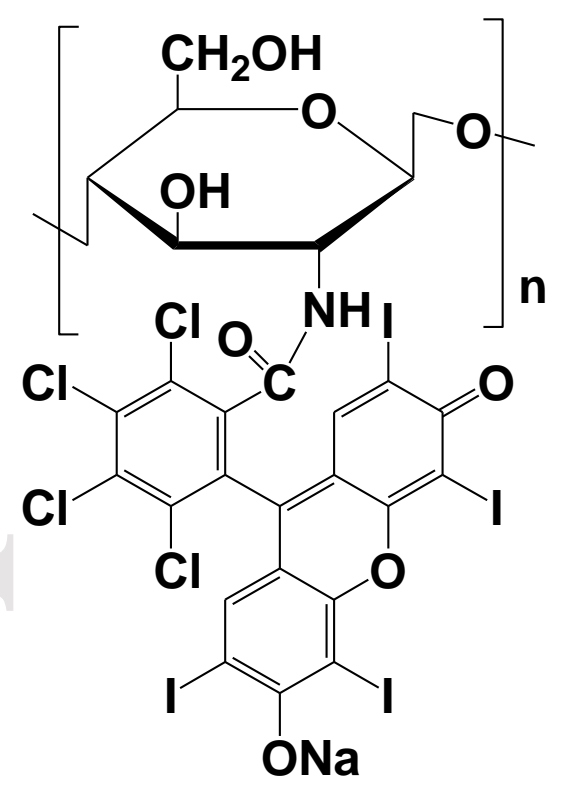

Scheme 2

This article is protected by copyright. All rights reserved. 